\title{
Resolução de problemas e sensoriamento remoto: em busca de uma aprendizagem ativa com estudantes do $9^{\circ}$ ano
}

\author{
Cassiano Scott Puhl - c.s.puhl@ hotmail.com - PUCRS \\ Thaísa Jacintho Müller - thaisa.muller@pucrs.br - PUCRS \\ Lori Viali - viali@pucrs.br - PUCRS \\ Regis Alexandre Lahm - lahm@pucrs.br - PUCRS
}

Resumo: Este artigo apresenta uma experiência didática interdisciplinar e inovadora, cujo objetivo foi de analisar a área desmatada nas comunidades em que os estudantes do $9^{\circ}$ ano de uma escola de Bom Princípio/RS residem. A pesquisa fundamentou-se nas tendências matemáticas modernas, como a Resolução de Problemas e as Tecnologias de Informação e Comunicação (TIC), utilizando a técnica de sensoriamento remoto. No decorrer da experiência didática, os estudantes entrevistaram pessoas, levantaram dados na web e utilizaram imagens orbitais do software Google Earth ${ }^{T M}$ para solucionar o problema. Por fim, os dados coletados apresentam fortes indícios que a Resolução de Problemas alinhada com as TIC são estratégias potencializadoras de uma aprendizagem ativa, formando estudantes críticos, criativos e preocupados com o meio em que vivem.

Palavras-chave: Resolução de problemas; Tecnologias na educação; Sensoriamento remoto; Imagens orbitais; Aprendizagem ativa.

\section{Problem solving and remote sensing: searching for active learning with 9th grade students}

\begin{abstract}
This article presents an interdisciplinary and innovative didactic experience, whose objective was to analyze the deforested area in the communities where the students of the 9th grade of a Bom Princípio / RS school reside. The research was based on modern mathematical trends, such as Problem Solving and Information and Communication Technologies (ICT), using the remote sensing technique. Throughout the didactic experience, students interviewed people, collected data on the web, and used orbital images of Google Earth ${ }^{\mathrm{TM}}$ software to solve the problem. Finally, the collected data present strong indications that Problem Solving aligned with ICT are strategies that promote active learning, forming students who are critical, creative and concerned about the environment in which they live.
\end{abstract}

Keywords: Problem Solving; Technologies in education; Remote sensing; Orbital images; Active learning.

\section{Introdução}

O ensino de Matemática que prevalece na escola não valoriza o conhecimento prévio do estudante, que é construído pelo contexto e pela realidade na qual está inserido (BÚRIGO et al., 2012). Nessa perspectiva, a Matemática, muitas vezes, é definida como um conjunto de fórmulas a serem decoradas e um conhecimento a-histórico, dificultando a aprendizagem dos conhecimentos matemáticos (VARRIALE; TREVISAN, 2012). Assim, faz-se necessário repensar a prática docente, criando estratégias de aprendizagem 
considerando a realidade do estudante e as principais vertentes da Educação Matemática do século XXI. Destacam-se a Resolução de Problemas, a utilização da História da Matemática, o emprego das Tecnologias de Informação e Comunicação, a Modelagem Matemática e a Etnomatemática.

Neste trabalho optou-se por utilizar a Resolução de Problemas, pois é uma estratégia de aprendizagem ativa que valoriza o conhecimento prévio do estudante, desenvolvendo as capacidades de reflexão, criatividade, autonomia e análise (ALLEVATO; ONUCHIC, 2014). Assim, o professor não é mais o transmissor do conhecimento, mas o motivador e mediador do processo. Além da Resolução de Problemas, considera-se oportuno a utilização das Tecnologias de Informação e Comunicação (TIC), pois segundo a Base Nacional Comum Curricular (BNCC) as TIC "[...] são instrumentos de mediação da aprendizagem e as escolas, especialmente os professores, devem contribuir para que o estudante aprenda a obter, transmitir, analisar e selecionar informações" (BRASIL, 2016b, p. 50), proporcionando um papel ativo ao estudante.

Neste trabalho apresenta-se o relato de uma experiência interdisciplinar ${ }^{1}$, com o nono ano do Ensino Fundamental da EMSJ (Escola Municipal São José), realizada na cidade de Bom Princípio/RS, cujo objetivo foi analisar a área desmatada no período de 2006-2016. Com a estratégia mencionada buscou-se desenvolver a reflexão dos estudantes na definição de hipóteses, a criatividade ao elaborar estratégias para a resolução do problema e a criticidade ao analisar os dados obtidos.

A escolha do tema, desmatamento, se justifica pois o IBGE (BRASIL, 2016a) relata que o município de Bom Princípio vem crescendo acima da média em termos populacionais. Entre 2007 e 2010 o crescimento foi de $8,1 \%$, enquanto que a população brasileira e a gaúcha cresceram, respectivamente 3,7\% e 1,0\%, aproximadamente, percentuais bem inferiores ao do município. Para abrigar os novos moradores, foi necessário abrir novos loteamentos e isso levou ao desmatamento de áreas verdes. Considerando o contexto do desmatamento no município, no qual os estudantes estão inseridos, criou-se o seguinte problema gerador: "na última década, em que proporção o desmatamento atingiu as comunidades onde residem os estudantes da EMSJ ${ }^{2}$ ?"

Visando a resolução do problema, surge a possibilidade da utilização das tecnologias para fins didáticos, permitindo que o estudante a acesse e a utilize na investigação do problema de pesquisa. Neste trabalho, utilizou-se as geotecnologias - um recurso que vem sendo cada vez mais utilizado pela sociedade -, sendo uma alternativa para o desenvolvimento de um trabalho interdisciplinar (BRASIL, 2016b). Nesse trabalho utilizou-se a técnica de sensoriamento remoto que consiste em uma "[...] tecnologia que permite a obtenção de informações sobre diferentes alvos ou fenômenos, na superfície da Terra e em sua atmosfera, sem o contato físico com os mesmos" (LAHM, 2000, p. 66). Assim, por meio de imagens de orbitais pode-se verificar o crescimento ou não da área desmatada do município. Essas imagens foram obtidas por intermédio do software Google Earth ${ }^{T M}$. A pesquisa proporcionou novos conhecimentos aos estudantes e aos professores orientadores, mas além disso, o trabalho tornou-se socialmente relevante, pois utilizou as tecnologias para conhecer e analisar as consequências do desmatamento nas comunidades em que residem os escolares.

\footnotetext{
${ }^{1}$ Segundo Fazenda (2009, p. 22): "A interdisciplinaridade pode ser compreendida como sendo um ato de troca, de reciprocidade entre as disciplinas ou ciências - ou melhor, de áreas do conhecimento".

2 A EMSJ está localizada no município de Bom Princípio, RS e abriga estudantes das comunidades dos bairros de Bom Fim Alto, Morro Tico-Tico, Nova Colúmbia e Piedade.
} 


\section{Fundamentação teórica}

Na Resolução de Problemas o ponto de partida para as atividades matemáticas em sala de aula é o problema. Ele é um meio para aprender novos conceitos criando um desafio para o estudante e gerando um conflito cognitivo, seja pela falta de conhecimentos ou por contradições entre os conhecimentos prévios dos estudantes e o problema proposto (ALLEVATO, 2014).

Ao utilizar a resolução de problemas, a função do professor é mais complexa, pois precisa pensar e propor um problema gerador que faça com que o estudante se sinta motivado e desafiado em resolvê-lo (FREITAS, 2008). Uma característica essencial para motivar os estudantes na resolução de problemas é levar em consideração a sua realidade ou seu contexto sociocultural. Segundo Pozo et al. (1998) a contextualização do conteúdo é essencial na Matemática, pois pode modificar e melhorar a qualidade da aprendizagem dos estudantes. Deste modo, o estudante tomará para si o problema e, consequentemente, inicia-se o processo da aprendizagem (FREITAS, 2008).

Complementado essa perspectiva, a BNCC afirma que a Resolução de Problemas permite que:

[...] o estudante adota uma postura ativa em relação ao próprio processo de construção do conhecimento matemático, direito essencial de suas aprendizagens. Ele desenvolve autonomia para realizar uma leitura crítica do mundo natural e social, que o instrumentaliza para a tomada de posições frente aos problemas sociais e ambientais que impactam sua vida e a de sua coletividade (BRASIL, 2016b, p. 133).

Conforme Becker (2015, p. 33-34), a aprendizagem humana inicia-se pela ação do estudante, pois: "A fonte da aprendizagem é a ação do sujeito, ou seja, o indivíduo aprende por força das ações que ele mesmo pratica: ações que buscam êxito e ações que, a partir do êxito obtido, buscam a verdade ao apropriar-se das ações que obtiveram êxito".

Desta forma, o estudante pode estabelecer relação entre o conteúdo matemático e o seu contexto sociocultural, sentindo-se inserido no processo de aprendizagem, assimilando e acomodando os conhecimentos explorados por meio das estratégias escolhidas para a resolução do problema. Sobretudo, considera-se que essas características podem dar consciência da importância desse conhecimento matemático e da validade do estudo na sua formação enquanto indivíduo. É esse discernimento, em relação a validade do estudo em nossas vidas, que pode proporcionar o entendimento da aplicabilidade ou do significado do conhecimento matemático.

$\mathrm{Na}$ Resolução de Problemas, além de construir novos conhecimentos, o estudante desenvolverá capacidades intelectuais e cooperativas (LURIA, 1990, p. 157). Ao solucionar o problema, o estudante faz uso da sua criatividade, desenvolvendo autonomia e habilidades de pensamento crítico, e preferencialmente, o problema será resolvido em um grupo, para estimular o trabalho cooperativo e a troca de conhecimentos.

Além da Resolução de Problemas, a pesquisa, fundamentou-se nas Tecnologias de Informação e Comunicação (TIC). Segundo Masseto (2013, p. 139):

[...] a tecnologia apresenta-se como meio, como instrumento para colaborar no desenvolvimento do processo de aprendizagem. A tecnologia reveste-se de um valor relativo e dependente desse processo. Ela tem sua importância apenas como um instrumento significativo para favorecer a aprendizagem de alguém. Não é a tecnologia que vai resolver ou solucionar o problema educacional do Brasil. Poderá colaborar, no entanto, se for usada adequadamente, para o desenvolvimento educacional de nossos estudantes 
Desta forma, as tecnologias não combinam com velhos hábitos (KENSKI, 2006), mas é necessário sua utilização fundamentada em perspectivas construtivista ou sociointeracionista (LIMA et al., 2014). Assim, busca-se uma aprendizagem ativa, em que o estudante interaja com os recursos tecnológicos, mas além disso, que pesquise, construa conceitos e troque conhecimentos com seus colegas, por meio do diálogo (MASSETO, 2013).

Desta forma, os recursos tecnológicos, principalmente o computador, não tem a função de reproduzir conteúdos ou técnicas, mas de proporcionar a "realização de aulas mais criativas, motivadoras, dinâmicas e que envolvam os alunos para novas descobertas e aprendizagem" (TAJRA, 2012, p. 46). Masseto (2013) corrobora com esta concepção, pois aborda que a tecnologia deve ser capaz de instaurar um ambiente reflexivo e investigativo, tornando as aulas mais interessantes e desafiadoras. Assim, percebe-se que a Resolução de Problemas e as TIC possuem características semelhantes, que permitem que professor e estudante construam novos conhecimentos e novas capacidades intelectuais.

Uma das áreas da Tecnologia, que vem crescendo em termos de sua utilização pela sociedade é das geotecnologias, principalmente de mapas interativos como o software Google Earth ${ }^{T M}$ (BRASIL, 2016b). Rosa (2009, p. 32) define geotecnologia como:

\footnotetext{
"conjunto de tecnologias para coleta, processamento, análise e disponibilização de informações com referência geográfica. São compostas por soluções de hardware, software e peopleware que juntas constituem-se em poderosos instrumentos como suporte a tomada de decisão. Dentre as geotecnologias podemos destacar: a cartografia digital, o sensoriamento remoto, o sistema de posicionamento global, o sistema de informação geográfica”.
}

O software Google Earth ${ }^{T M}$ foi o escolhido para ser utilizado nessa pesquisa, pois é uma ferramenta versátil e de potencial pedagógico tornando-se um recurso para realizar a análise espacial. Assim, optou-se por uma tecnologia pouco explorada na resolução de problemas na matemática, mas que possui potencial para a construção de novos conhecimentos, que é o sensoriamento remoto, pois pode contextualizar a aprendizagem de determinado conhecimento. Desse modo, o estudante participará ativamente nesse processo, visualizando, analisando e concluindo sobre as informações disponíveis por meio de imagens orbitais (GIL; BAZZAN; LIMA; LAHM, 2012).

O sensoriamento remoto é uma técnica que por meio das geotecnologias, permite a realização de um estudo sem que o pesquisador se desloque até determinado local, acessando as informações de forma sinóptica, por exemplo; utilizando imagens orbitais via satélite. $\mathrm{Na}$ educação, a utilização de geotecnologias oportuniza aos estudantes participarem e construírem seus conhecimentos por meio de uma proposta inovadora ${ }^{3}$ de cunho interdisciplinar. Além disso, desenvolve o senso reflexivo e crítico dos estudantes, pois estudarão sobre o contexto no qual estão inseridos na sociedade (SCHLEICH, 2015).

\section{Materiais e métodos}

A pesquisa foi desenvolvida durante o segundo trimestre do ano de 2017 e teve como participantes 21 estudantes de uma turma do nono ano de uma escola municipal de

\footnotetext{
${ }^{3}$ Segundo Behrens (2013, p. 75): “[...] o professor, ao propor uma metodologia inovadora, precisa levar em consideração que a tecnologia digital possibilita o acesso ao mundo globalizado e à rede de informação disponível em todo o universo".
}

V. $15 \mathrm{~N}^{\circ}$ 2, dezembro, 2017 
ensino fundamental, situada no município de Bom Princípio, estado do Rio Grande do Sul.

A pesquisa é de cunho qualitativo, pois não se propõe a testar e comprovar hipóteses, mas procura compreender o fenômeno estudado no contexto social inserido, por meio da elaboração de asserções, que correspondam aos objetivos do projeto de pesquisa (BORTONI-RICARDO, 2008). Com base nestas considerações utilizaram-se diferentes instrumentos de coleta de dados, buscando, assim, uma descrição mais apropriada da realidade estudada (FAZENDA, 2010). Os instrumentos de coleta de dados utilizados foram observações diretas e fotografias. Visando atingir o objetivo da pesquisa, organizaram-se as seguintes etapas:

1. Realizar um levantamento bibliográfico sobre biomas brasileiros, o desmatamento no Rio Grande do Sul e os animais em extinção;

2. Entrevistar pessoas das comunidades, para reconhecer a área da mata e os animais selvagens que, frequentemente, apareciam nas casas há, pelo menos, dez anos atrás;

3. Transcrever a fala das pessoas entrevistadas, analisando as convergências e divergências nas entrevistas;

4. Conhecer o software Google Earth ${ }^{T M}$ e seus recursos, marcando pontos referentes aos limites onde moram os estudantes da EMSJ;

5. Imprimir as imagens orbitais que delimitam as fronteiras das comunidades mapeadas anteriormente, dos anos de 2006 e de 2016;

6. Elaborar mapas, com a superfície de mata e da região urbana dos anos de 2006 e de 2016, como também, analisar as respectivas áreas;

7. Analisar as respectivas imagens e mapas, e divulgar num ambiente virtual, disponibilizado em https://sites.google.com/site/91mostratec/.

\section{Resultados e discussões}

Na busca da resolução do problema, os estudantes buscaram informações na biblioteca universal, a $\mathrm{WWW}^{4}$. Na busca tiveram o conhecimento do aumento populacional e descobriram, também, que o bioma do qual o município faz parte é o da Mata Atlântica e verificaram qual o desmatamento da mesma. Durante a busca, os estudantes acessaram sites governamentais, como o Instituto Brasileiro de Geografia e Estatística (IBGE) e o Ministério do Meio Ambiente, buscando dados que pudessem ser utilizados na solução do problema.

Realizado o levantamento bibliográfico, os estudantes saíram a campo e entrevistaram moradores das comunidades que a escola abriga - Morro Tico-Tico, Nova Colúmbia, Piedade e Bom Fim Alto - para reconhecer a área da mata e os animais selvagens que, frequentemente, apareciam nas casas dos moradores há cerca de dez anos. Após a entrevista, realizou-se a transcrição literal das mesmas, como também, analisaram-se os dados (Figura 1).

Por meio das entrevistas, concluiu-se que as comunidades Morro Tico-Tico e Nova Colúmbia sofreram desmatamento nas últimas décadas, principalmente pela urbanização dessas comunidades. Para exemplificar essa situação traz-se um relato de um dos entrevistados: "Para fazer a comunidade crescer e evoluir mais, foram construídas creches, campos de futebol, ginásios de esportes, novas escolas, e muitas construções de empresas para o crescimento da comunidade em geral". Em compensação, as

\footnotetext{
${ }^{4}$ Segundo Tajra (2012, p. 131): “A WWW (World Wide Web): é uma grande teia que liga várias mídias (textos, imagens, animações, sons e vídeos) simultaneamente, formando um imenso hipertexto. Esse serviço é composto pelas páginas, também conhecidas como homepage ou sites".
} 
comunidades de Piedade e Bom Fim Alto não sofreram com o desmatamento, pois as comunidades não cresceram tanto em termos populacionais, segundo os entrevistados.

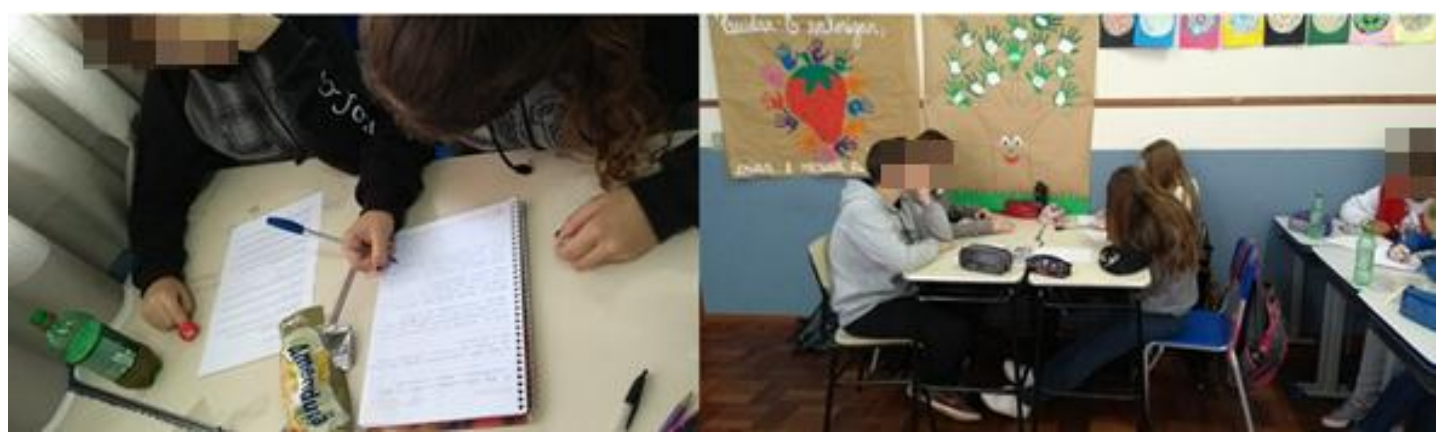

Figura 1 - Estudantes analisando as entrevistas

A urbanização acabou afetando a aparição de animais silvestres que antigamente, frequentemente, estavam presentes na comunidade, como: o macaco-prego (Sapajus), o ratão-do-banhado (Myocastor coypus), o preá (Cavia aperea), o porcoespinho (Coendou prehensilis), o tatu-peba (Euphractus sexcintus), o tatu-mulita (Dasypus hybridus), o tucano-toco (Ramphastos toco), o sagui (Callithrix), a lontra (Lontra longicaudis), a saracura (Aramides saracura), o nambu (Inhambu-chororó) e o pombo (Columba livia). Preocupados com esse cenário, os estudantes realizaram um levantamento no site ${ }^{5}$ da União Internacional para Conservação da Natureza e dos Recursos Naturais (IUCN) para verificar quais animais estão na lista vermelha de espécies ameaçadas, encontrando: o tatu-mulita (pouco preocupante), tatu-pega (pouco preocupante), preá (pouco preocupante), ratão do banhado (pouco preocupante), tucanotoco (pouco preocupante) e lontra (quase ameaçada).

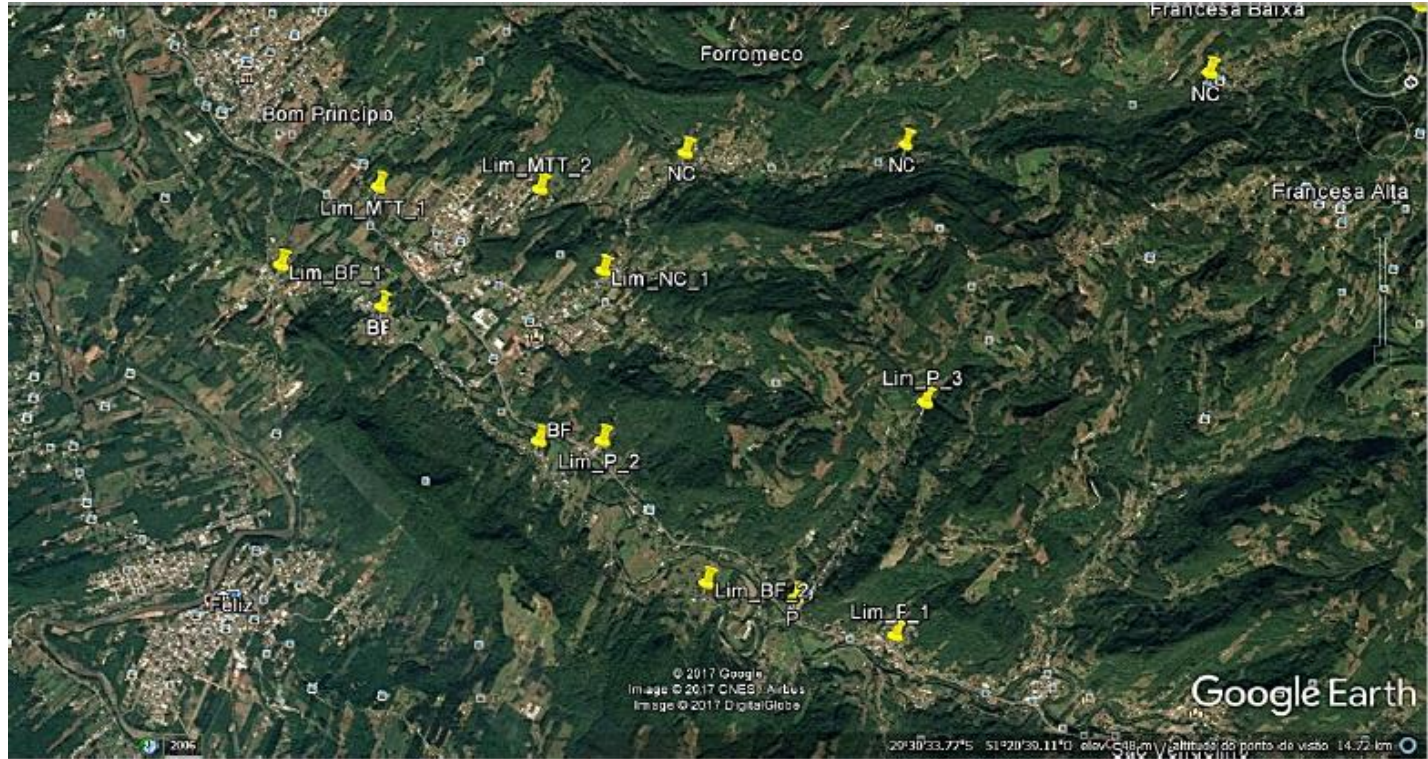

Figura 2 - Região mapeada pelos estudantes

Reconhecido o contexto no qual o município está inserido e preocupados com essa situação, os estudantes mapearam as regiões das comunidades que a EMSJ contempla, por meio do software Google Earth ${ }^{T M}$. O mapeamento dessa região foi um processo demorado, pois além de limitar as comunidades, os estudantes tiveram o cuidado

\footnotetext{
${ }^{5}$ Disponível em: <http://www.iucnredlist.org/>.
} 
para não gerar imagens em uma escala pequena, o que dificultaria o processo de análise das imagens orbitais. A Figura 2 apresenta a região mapeada, sendo que essa imagem foi dividida em outras 11, totalizando 22 imagens para análise, metade do ano de 2006 e a outra metade do ano de 2016.

Visando facilitar a análise das imagens, os estudantes criaram seus próprios mapas, utilizando folhas transparentes (ovewrlay) de retroprojetor e pincéis marcadores permanentes. A construção do mapa é um procedimento que requer concentração e a precisão, atitudes essas contempladas pelos estudantes, como é observado na Figura 3. Durante a realização dos mapas, os estudantes perceberam a necessidade da elaboração de legendas para melhor compreendê-los, marcando os seguintes elementos: os fragmentos de mata, as estradas visíveis e a área urbana (construções e residências).

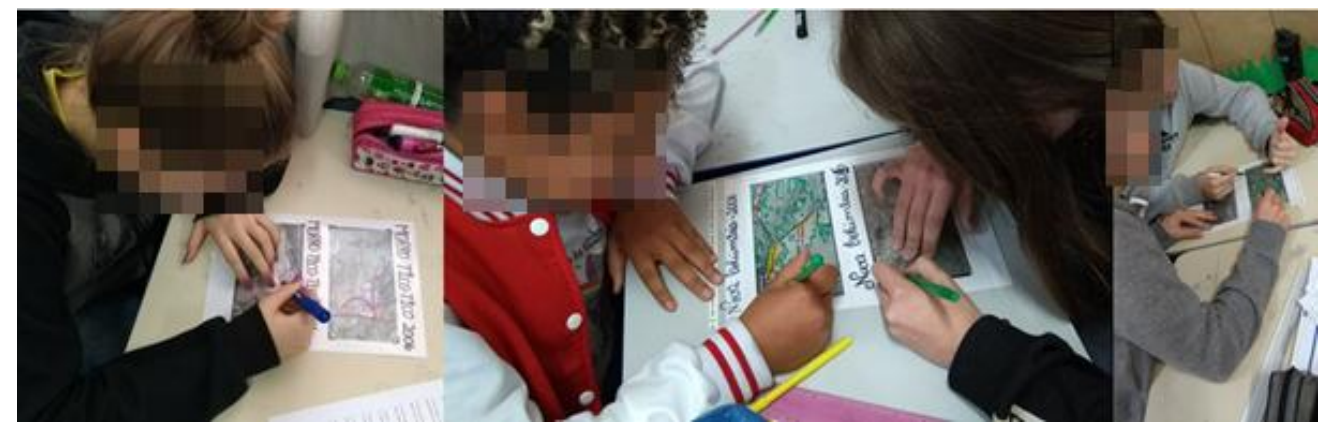

Figura 3 - Estudantes elaborando os mapas

Por meio dos mapas, tinha-se o objetivo de calcular aproximadamente a área de mata presente em cada comunidade, e comparar os resultados de 2006 e de 2016. Já se previa dificuldades nos cálculos, pois as áreas provavelmente teriam curvas, não seriam representadas por um polígono, como mostra a Figura 4.

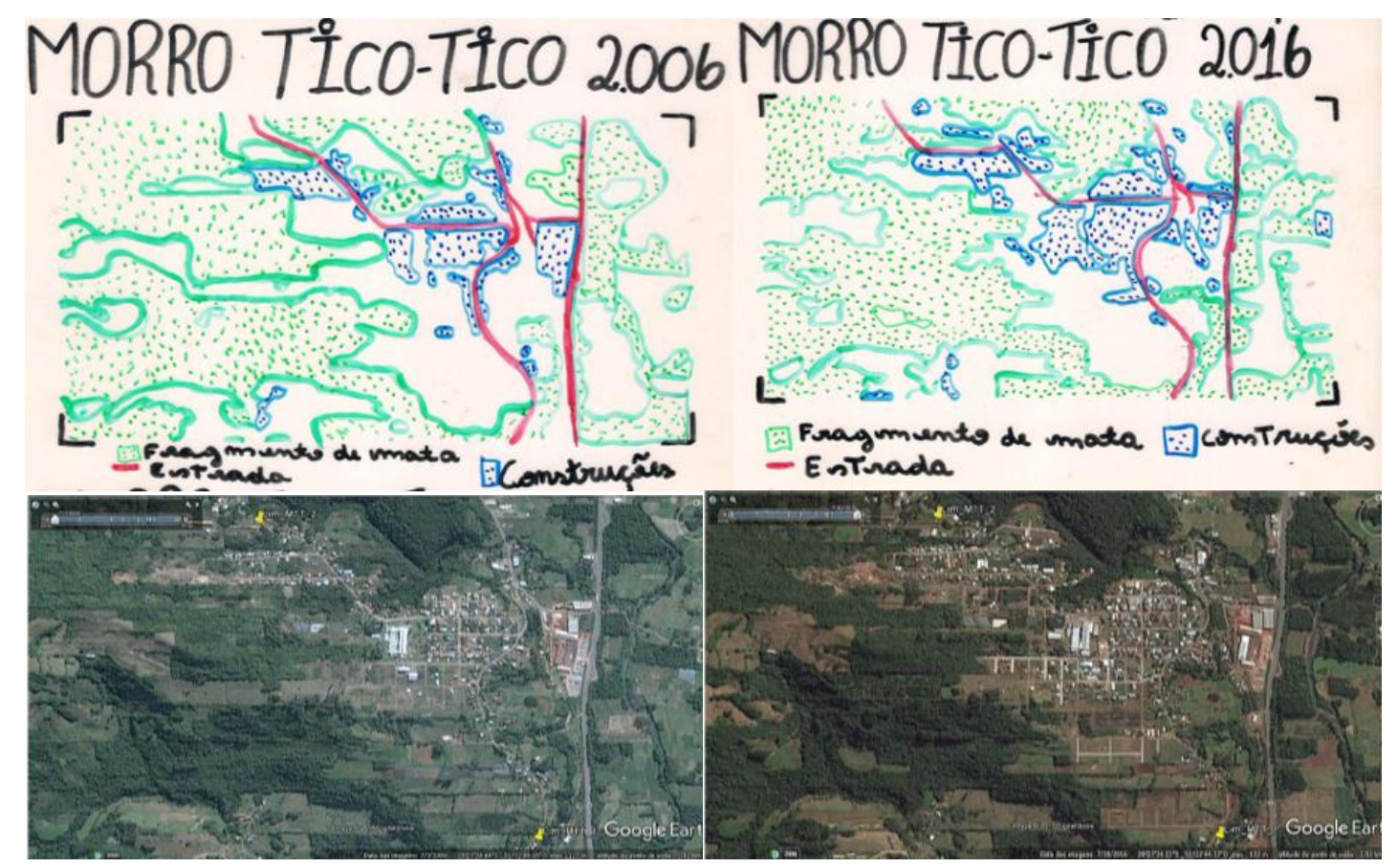

Figura 4 - Um mapa construído pelos estudantes

Os estudantes discutiram e planejaram uma estratégia para determinar a superfície de fragmento de mata, que consistiu em determinar a área total do mapa e diminuir da região desmatada, sendo esse um problema, pois a região desmatada não se 
aproxima de uma forma geométrica convencionalmente estudada em Matemática. Buscando um modo de solucionar esse problema, os estudantes utilizaram papel vegetal e marcaram a região desmatada, após recortaram as regiões e juntaram os recortes até que formasse uma figura na qual saberiam calcular a área aproximada. Porém, como o processo de cálculo ficou difícil e trabalhoso, até mesmo para determinar a área aproximada, decidiu-se realizar uma análise comparativa, utilizando a técnica do sensoriamento remoto.

Analisando as imagens orbitais e os mapas criados, concluiu-se que os fragmentos de mata aumentaram nas comunidades, ou seja, não houve desmatamento nessa última década. A hipótese que tinham do desmatamento na última década era falsa, o que deixou os estudantes impressionados, como também os professores orientadores que levantaram algumas questões: "Quais são as causas do aumento da mata? Ou será que a mata assinalada nos mapas é realmente mata nativa?".

Certamente, para responder essas questões seria necessário mais um projeto de pesquisa com os estudantes, mas surpreendidos (professores e estudantes) com tal resultado, organizou-se uma saída de campo (Figura 5) para confirmar a existência de mata exótica na região, prejudicando o crescimento do bioma natural.

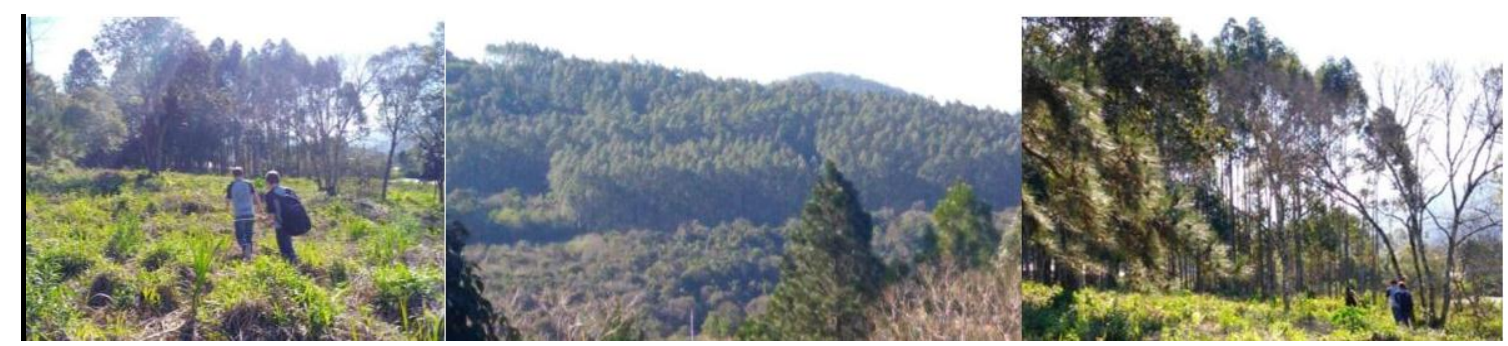

Figura 5 - Saída de campo com a professora de Ciências

Em relação ao aumento populacional, as comunidades de Morro Tico-Tico e Nova Colúmbia cresceram de uma forma mais acentuada, conforme também foi averiguado nas entrevistas. Uma hipótese levantada pelos estudantes é que o aumento populacional nessas comunidades se deve ao investimento público realizado nessas comunidades, como: a construção de escolas (infantil e fundamental); postos de saúde; praças; ginásios de esportes; além da abertura de ruas para loteamentos. As comunidades de Bom Fim Alto e Piedade não tiveram um aumento considerável de casas e loteamentos, provavelmente, por estarem mais de pequenas empresas e do centro do munícipio.

Por fim, para sintetizar e divulgar o trabalho desenvolvido, criou-se um site denominado "Desmatamento nas comunidades da Escola São José", disponível em: $<$ https://sites.google.com/site/91 mostratec/home>. Deste modo, aproveitou-se mais uma vez a tecnologia para salvar e compartilhar os resultados da pesquisa na WWW.

\section{Considerações finais}

A Resolução de Problemas é uma tendência da Educação Matemática que modifica o ambiente escolar, transformando o estudante em sujeito ativo da sua aprendizagem. Assim, é possível a criação de estruturas de assimilação para a acomodação do novo conhecimento na estrutura cognitiva. Por meio da descrição das atividades, pode-se perceber a ação do estudante em todas as fases do projeto, e também a observação em sala de aula permitiu concluir que todos os estudantes enfrentaram, de fato, o desafio de resolver o problema gerador: "na última década, em que proporção o desmatamento atingiu as comunidades residenciais dos estudantes da EMSJ?". 
Porém, sem a utilização das tecnologias a resolução do problema seria inviável. Deste modo, as TIC possuem um grande potencial para a aprendizagem de novos conhecimentos, sendo um facilitador na resolução de problemas da realidade dos estudantes. Nesta pesquisa, as tecnologias utilizadas não foram um mero recurso motivacional, mas com objetivos pedagógicos, em que os estudantes obtiveram informações para fazer uma comparação e uma análise, para a construção de novos conhecimentos.

Mesmo que os estudantes não tenham encontrado uma resposta definitiva para o problema de pesquisa, considera-se que se obteve êxito no trabalho, pois estudantes colocaram-se como pesquisadores, realizando todas as etapas propostas e utilizando seus conhecimentos e sua criatividade para resolver problemas secundários que aparecerem no decorrer da pesquisa. Além disso, os estudantes vivenciaram que os conhecimentos matemáticos desenvolvidos no ambiente escolar podem ser insuficientes para retratar com precisão as situações reais. Assim, tiveram que utilizar outra estratégia para resolver parcialmente o problema, que foi a análise comparativa, sendo necessário que o estudante inovasse e utilizasse sua criatividade para resolver o problema.

Deste modo, planejou-se e aplicou-se uma proposta inovadora e interdisciplinar no ensino de Ciências e Matemática, indo além da aprendizagem de conteúdos curriculares, proporcionando ao estudante o desenvolvimento de sua criatividade e de seu senso crítico, capacitando-o a agir conscientemente na sociedade e no meio ambiente. Nesta experiência didática, conclui-se que a Resolução de Problemas aliada as TIC foram um alicerce para a formação de estudantes do século XXI, pois além do conhecimento conceitual, desenvolveram atitude e comportamentos importantes para o novo perfil de cidadão que se pretende formar, como: a criatividade, a criticidade e a autonomia.

\section{Referências}

ALLEVATO, N. S. G. Trabalhar através da resolução de problemas: possibilidades em dois diferentes contextos. VIDYA, Santa Maria, v. 34, n. 1, p. 209-32, 2014.

ALLEVATO, N. S. G.; ONUCHIC, L. de La Rosa. Ensino-Aprendizagem-Avaliação de Matemática: por que Através da Resolução de Problemas? In: ONUCHIC, L. de La Rosa et al (Org.). Resolução de Problemas: teoria e prática. Jundiaí (SP): Paco Editorial, 2014.

BECKER, F. Educação e construção do conhecimento. $2^{a}$ ed. Porto Alegre (RS): Penso, 2015.

BEHRENS, M. A. Projetos de aprendizagem colaborativa num paradigma emergente. In: MORAN, J. M.; MASETTO, M. T.; BEHRENS, M. A. (Org.). Novas tecnologias e mediação pedagógica. $21^{\mathrm{a}}$ Ed. Campinas (SP): Papirus, 2013.

BORTONI-RICARDO, S. M. O professor pesquisador: introdução à pesquisa qualitativa. São Paulo (SP): Parábola, 2008.

BRASIL. Instituto Brasileiro de Geografia e Estatística (IBGE). Cidades@. 2016a. Disponível em:

$<$ http://cidades.ibge.gov.br/xtras/perfil.php?lang=\&codmun=430235\&search=riogrande-do-sul|bom-principio>. Acesso em: 20 out. 2017. 
BRASIL. Ministério da Educação. Base Nacional Comum Curricular: proposta preliminar. 2. ed. Brasília: MEC, $2016 \mathrm{~b}$.

FAZENDA, I. C. A. Metodologia da pesquisa educacional. 12 a ed. São Paulo (SP): Cortez, 2010.

FAZENDA, I. C. A. Práticas interdisciplinares na escola. $11^{a}$ ed. São Paulo (SP): Cortez, 2009.

FREITAS, J. L. M. Teoria das Situações Didáticas. In: MACHADO, S. D. A. (Org.). Educação Matemática: Uma (nova) introdução. $3^{\text {a }}$ ed. São Paulo (SP): EDUC, 2008.

GIL, K. H.; BAZZAN, T; LIMA, V. M. do R.; LAHM, R. A. Aprendizagem apoiada por computador: ensinando geometria plana através de imagens orbitais. CINTED, Porto Alegre, v. 10, n. 1, jul. 2012.

LAHM, R. A. Técnicas de Sensoriamento remoto e geoprocessamento aplicados a cartografia. In: CASTROGIOVANNI, A. C. Inquietações Geográficas. (pp. 65-75). Porto Alegre (RS): Dos Autores, 2000.

LIMA, J. V. de et al (Org.). Objetos de aprendizagem multimodais: projetos e aplicações. Barcelona (Espanha): Editorial UOC, 2014.

LURIA, A. R. Desenvolvimento cognitivo: seus fundamentos culturais e sociais. São Paulo (SP): Ícone, 1990.

MASSETO, M. T. Mediação Pedagógica e Tecnologias de Informação e Comunicação. In: MORAN, J. M.; MASETTO, M. T.; BEHRENS, M. A. (Org.). Novas tecnologias e mediação pedagógica. 21 ${ }^{\mathrm{a}}$ Ed. Campinas (SP): Papirus, 2013.

POZO, J. I. et al. A solução de problemas: aprender a resolver, resolver para aprender. Porto Alegre (RS): Artmed, 1998.

ROSA, R. Geomatica no Brasil: histórico e perspectivas futuras. GeoFocus. Revista Internacional de Ciencia y Tecnología de la Información Geográfica, Barcelona (Espanha), v. 1, n. 9, 2009.

SCHLEICH, Á. P. Educação ambiental em um clube de ciências, utilizando geotecnologias. 2015. Dissertação (Mestrado) - Pontifícia Universidade Católica do Rio Grande do Sul, Programa de Pós-Graduação em Educação em Ciências e Matemática, 2015.

TAJRA, S. F. Informática na educação: novas ferramentas pedagógicas para o professor na atualidade. 9. ed., rev., atual. e ampl. São Paulo (SP): Érica, 2012.

VARRIALE, M. C.; TREVISAN, V. Novos conteúdos e novas abordagens. In: BÚRIGO, E. Z. et al (Org.). A matemática na escola: novos conteúdos, novas abordagens. Porto Alegre (RS): Ed. UFRGS, 2012. 